\title{
Contracting and Copyright Issues for Composite Semantic Services
}

\author{
Christian Baumann* \\ SAP AG, SAP Research CEC Karlsruhe \\ Vincenz-Prienitz-Str. 1, 76131 Karlsruhe, Germany \\ ch. baumann@sap.com
}

\begin{abstract}
In business webs within the Internet of Services arbitrary services shall be composed to new composite services and therewith creating tradeable goods. A composite service can be part of another composite service and so on. Since business partners can meet just for one transaction not having regular business which justifies frame contracts, ad-hoc automated contracting needs to be established. In addition services have an intangible character and therefore are prone to illegal reproduction. Thus intellectual property rights have to be considered.

Our research approach is to assess the applicability of copyright law for semantic web services and develop a concept for automated contracting. Methodologies to be used are in the field of ontology modeling and reasoning.
\end{abstract}

Keywords: semantic web service, intellectual property rights, copyright, automated contracting.

\section{Research Problem}

The interconnectivity utilized by internal networks or the internet and the rise of Service-oriented architectures (SOA) lead to changes in e-business. Reusable components - so called services - can be used to compose individual applications (composite services) fitting for a specific problem. Recently semantic technology is applied to provide semantic services, which allow to more efficiently build composite services out of atomic services. This contributes to the vision of the Internet of Services (IoS) [13] 8], where services become similar to tradeable goods on the internet.

However, the building blocks of the IoS, the services, are more than just technical web services. Services comprise business models, business processes and a technical aspect (see Figure 1) to enable a business web 11. With the rise of such new business areas participants have substantial interest in the protection of their own (intangible) property, such as copyright. This challenges jurisdictions to provide a legal framework within which business web participants can trade and conclude contracts safely. Typically existing legal regulations are being transfered

\footnotetext{
* The project was funded by means of the German Federal Ministry of Economy and Technology under the promotional reference "01MQ07012". The authors take the responsibility for the contents.
} 
to newly risen business areas, and, if not possible, extended or newly created and passed by the jurisdiction. The advance in information technology, for example, required an adaption in copyright laws worldwide in the past decade, because the costs for information exchange and duplication of digitally recorded work became insignificant [12, pp. 2-3].

The IoS is envisioning a business web with seamless businessto-business (B2B) integration by semantic information exchange and arbitrary reusability of an intangible, tradeable good: the service. To realize the vision, intensive research is currently undertaken. The project TEXO1 within the research program THESEUS, for example, looks into business webs in the IoS. Within such a business web some

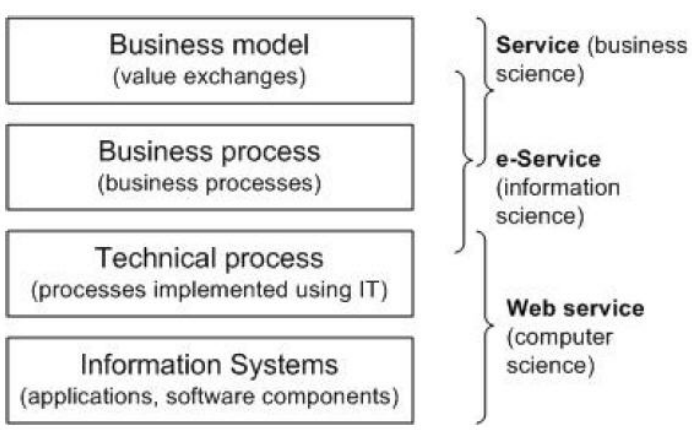

Fig. 1. Service Categorization [1] services are thought to being composed, e.g. the services $a, b, c$, to a composite service, e.g. $s$. These services may all be provided by some legally independent entities, $A, B, C$ and $S$. The composite service $s$ may also be part of another composite service, let us say $z$. This short illustration shows the complexity of the IoS and gives an idea on how important representation and control over one's own intellectual property is. Maybe $A, B, C$ do not want to be included in a mashup $z$ or at least receive some payment for this.

Furthermore not only the technology for automated composition of a composite service is required, but also the legal foundation of concluding contracts. Typically frame contracts are being negotiated offline and only afterwards automated negotiation of some service levels is carried out. However, in the IoS this is not sufficient, since business partners may meet just for one transaction, and therefore an explicit offline negotiation of contracts causes too high transaction costs. Hence an automated way for contracting in the IoS is required, with which participants are able to meet on the same eye level, which prevents dominant players.

The example above even shows two different contracts. Let us assume the legal entity $Z$ is the customer of $S$, integrating $s$ in his own composite service $z$. Internally $A, B, C$ and $S$ have to conclude a contract, externally $S$ and $Z$ also need to conclude a contract. In this scenario, the intellectual property rights need to be considered and passed through during automated contracting.

This leads us to the research problem we want to discuss:

1. In a scenario of collaborative development of new (composite) web services (trade goods), current copyright law is adequate as a legal foundation to protect the exploitation rights of one's own web service.

2. The non-functional property exploitation rights can be represented and formalized with semantic technology for being utilized during automated contracting of service composition. Sound modeling with e.g. ontologies can

\footnotetext{
${ }^{1}$ http://theseus-programm.de/scenarios/en/texo/, visited 05.05.2008.
} 
provide abstractness and flexibility for later extension for the implementation of automated contracting.

Ensuring an adequate handling of exploitation rights can raise trust and transparency in the IoS, therewith boosting its innovation power and give an incentive for participation.

\section{Related Work}

This section discusses state of the art in the field of copyright and contracting issues for composite semantic services. First, legal aspects are depicted, then related work in the area of semantic web is looked at.

The concept of a web service has taken little notice in the jurisprudence 2 so far. The same is true for the extension with a semantic annotation or the development of composite web services within SOA. The categorization of web services to a special type of contract is an open research question, e.g. [9] is discussing aspects of different contract types. The categorization is important because of the transfer of rights of the contractual object and the further use of this intellectual property. Also collaborative composite service development is not explicitly discussed. For linking and framing of websites copyright law is applicable, e.g. [11, however, this is not settled for composite services and an interesting question for the thesis.

In the research project SESAM 3 self organizing distributed electronic markets in the area of power markets were analyzed. One outcome of the research is the concept of an electronic legal mediator [5] for the process of concluding contracts without any offline steps [4]. This was required, since no central instance was available and contracts had to be concluded hourly. Thus software agents were designed to perform the negotiations between different parties. In contrast to power markets the IoS is, however, not as regulated and has a much lower entry barrier for new participants. As a result the electronic legal mediator is not suitable for on open business web in the IoS, since it only covers a very specific area of contracting in the power market. The IoS, however, requires a flexible framework for automated contracting and the management of intellectual property for the development of composite services.

The research project TrustCoM 4 was put up to build an environment for trust, security and contract management for B2B collaboration based on SOA. The main legal aspect was to enforce and monitor contracts for virtual organizations. This was achieved by implementing contractual terms and conditions as policies within the SOA infrastructure. These common regulations provide transparency for the virtual organizations facilitating trust. Moreover a risk management to reduce uncertainty in regards to the applicable statuary laws is provided. To provide predefined terms for the automated contracting in order to facilitate

\footnotetext{
${ }^{2}$ In this discussion we limit the legal scope to german jurisdiction.

${ }^{3}$ http://www.internetoekonomie.uni-karlsruhe.de/, visited 08.05.2008.

${ }^{4}$ http://www.eu-trustcom.com/, visited 08.05.2008.
} 
trust is a concept we also pursue, however, in TrustCoM "negotiation involves only the SLA, with no reference to the other non-operational aspects of the collaboration that would normally appear in a legal document" [3, p. 29]. These non-operational aspects are the non-functional properties we want to enable, also including negotiation capabilities of intellectual property aspects for composite services.

Automated contracting facilitated by semantic technologies is shown in 10 . Lamparter is using his own core policy ontology, a ontology of bids and a contract ontology, which are based on the foundational ontology DOLCE5. Although automated matchmaking and contract formation using semantic annotation is achieved, a pre-negotiated "umbrella contract" [10, p. 123] is set as a precondition. The contracting process is only covering some functional service level agreements, leaving non-functional contractual terms for the offline negotiation of the umbrella contract. Intellectual property rights for service composition is not considered.

In the area of semantic web and law a lot of work is done in the representation of legal knowledge. A key challenge is to give access to existing judgments and represent regulations for educational training of young judges [2. Also design patterns for legal ontology construction are discussed [6]. Laarshot et al. 14 tried to bridge the gap between legal concepts and actual cases to advice with ontology-based reasoning on possible liability situations. The works mentioned do not discuss automated contracting and representation of intellectual property rights in the semantic environment. However, their work is important for the formalization of legal aspects.

As a foundational ontology in the area of modeling legal aspects, the Legal Knowledge Interchange Format (LKIF) is enabling the translation between legal knowledge bases [7. It is based on the foundational ontology DOLCE. The LKIF consists of a combination of OWL-DL and SWRL. We think LKIF is a good foundation for further formalization in the area of automated contracting and representation of intellectual property rights.

\section{Contribution and Evaluation}

The results of the research problem as stated in Section 1 will be integrated into the research program THESEUS6, project TEXO. The legal analysis in copyright law will be reflected in the ontology for the service description framework. The techniques for formalization and reasoning over exploitation rights will make a contribution to the overall context of automated contracting during composition of semantic web services. The methodologies used will be in the field of ontology modeling and reasoning to find possible collisions during negotiation and enabling a management of intellectual property rights during contracting.

The evaluation will also be carried out within the project TEXO. The use case scenario "Eco Calculator" of the project comprises composition of semantic web

${ }^{5}$ http://www.loa-cnr.it/DOLCE.html/, visited 08.05.2008.

${ }^{6}$ http://theseus-programm.de/, visited 05.05.2008. 
services including different legal entities and an end customer. The scenario will be used to justify the legal analysis and serve as an evaluation for the topic of automated contracting for semantic web services, in particular the exploitation of intellectual property rights.

\section{Work Plan}

The Ph.D. thesis is located in between the research areas of law and the semantic web. Figure 2 illustrates the interdisciplinary research field. The academic research partners are from Universitt Karlsruhe $(\mathrm{TH}) 7$ : In the area of intellectual property "Institute for Information Law"8 and for the semantic web domain "Institute of Applied Informatics and Formal Description Methods" (AIFB)9.

Following different phases of the Ph.D. thesis are outlined. It is differentiated into current status, work in progress and planned work.

Current Status. The overall work time for the Ph.D. thesis is planned to be three years. Three months have passed now. The current status is as outlined in this paper.

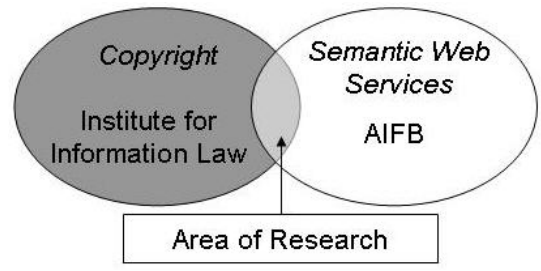

Fig. 2. Interdiciplinary Research Area

Work in Progress. The current work is to investigate and assess the applicability of copyright law for collaborative semantic service development. The scope is set to german copyright law, with the option to extend to international copyright acts. In parallel the possibilities of formalization of such intellectual property rights for semantic web services is assessed. The next planned step is a paper in 2008 to discuss copyright issues for collaborative semantic web service development.

Planned Work. Until end of 2008 the utilization of semantic modeling of intellectual property rights and semantic reasoning during automated contracting is planned to be assessed. Until 2009/12 the legal analysis and the concept for the technical formalization of intellectual property rights within the context of semantic services shall be finished. Until 2010/12 the concept of automated contracting and the incorporation of intellectual property rights into the contracting process shall be ready. The Ph.D. thesis manuscript is planned to be available in $2011 / 02$.

\section{References}

1. Baida, Z., Gordijn, J., Omelayenko, B.: A shared service terminology for online service provisioning. In: Janssen, M., Sol, H.G., Wagenaar, R.W. (eds.) ICEC. ACM International Conference Proceeding Series, vol. 60, pp. 1-10. ACM, New York (2004)

\footnotetext{
${ }^{7}$ http://www.uni-karlsruhe.de/, visited 09.05.2008.

8 http://www.zar.uni-karlsruhe.de/iirdreier/, visited 09.05.2008.

${ }^{9}$ http://www.aifb.uni-karlsruhe.de/english/, visited 09.05.2008.
} 
2. Blázquez-Cívico, M., Pena-Ortiz, R., Contreras-Cino, J., Benjamins, V.R.: Iuriservice - Architecture: A Knowledge Management System for Spanish Judicial Domain. In: Casanovas, P., Noriega, P., Bourcier, D., Galindo, F. (eds.) Trends in Legal Knowledge, Florence, Italy, pp. 243-261. European Press Academic Publishing (2007)

3. Cojocarasu, D.I., NRCCL: Final report on legal issues - Enforcing and monitoring of VO Contracts. In: TrustCoM (2005)

4. Conrad, M., Funk, C., Raabe, O., Waldhorst, O.P.: A Lawful Framework For Distributed Electronic Markets. In: Camarinha-Matos, L.M., Afsarmanesh, H., Novais, P., Analide, C. (eds.) Virtual Enterprises and Collaborative Networks. IFIP, vol. 243, pp. 233-240. Springer, Heidelberg (2007)

5. Dietrich, A., Lockemann, P.C., Raabe, O.: Conceptual Modelling in Information Systems Engineering. In: Agent Approach to Online Legal Trade, pp. 177-194. Springer, Heidelberg (2007)

6. Gangemi, A.: Design Patterns for Legal Ontology Construction. In: Casanovas, P., Noriega, P., Bourcier, D., Galindo, F. (eds.) Trends in Legal Knowledge, Florence, Italy, pp. 171-191. European Press Academic Publishing (2007)

7. Hoekstra, R., Breuker, J., Di Bello, M., Boer, A.: The LKIF Core Ontology of Basic Legal Concepts (June 2007)

8. Janiesch, C., Ruggaber, R., Sure, Y.: Eine Infrastruktur für das Internet der Dienste. HMD - Praxis der Wirtschaftsinformatik 261, 71-79 (2008)

9. Koch, F.A.: Web Service als neue IT-Vertragsleistung - Definition und vertragstypologische Einordnung von Web Service-Anwendungenn. IT-Recht kompakt 3, 71$73(2007)$

10. Lamparter, S.: Policy-based contracting in semantic web service markets. Universitätsverlag Karlsruhe (2007)

11. Ott, S.: Urheber- und wettbewerbsrechtliche Probleme von Linking und Framing. Boorberg (2003)

12. Pierson, M., Ahrens, T., Fischer, K.: Recht des geistigen Eigentums. Vahlen (2007)

13. Ruggaber, R.: Internet of Services SAP Research Vision. WETICE, 3 (2007)

14. van Laarshot, R., van Steenbergen, W., Stuckschmidt, H., Lodder, A.R., van Harmelen, F.: The Legal Concepts and the Laymans Terms - Bridging the Gap through Ontology-Based Reasoning about Liability. In: JURIX 2005 (2005) 